STEENBOCK, W.; VEZZANI, F.M. Agrofloresta: aprendendo a produzir com a natureza. Curitiba: Fabiane Machado Vezzani, 2013.

TEIXEIRA, R. A.; COUTO, M. S. D. S. Análise dos impactos socioeconômicos e ambientais da expansão da cana-de-açúcar na Bacia do rio Meia Ponte, Goiás. Revista Terceiro Incluído, v.3, n.1, p. 128-143, 2013.

\section{PRODUÇÃO ORGÂNICA: UMA ESTRATÉGIA SUSTENTÁVEL E COMPETITIVA PARA A AGRICULTURA FAMILIAR}

Clayrmen Candido Peron ${ }^{I}$ Jacqueline Priscila Olmedo ${ }^{2}$ Marcelo Marques Dell'acqua

Flávio Luís Grava Scalco Janaina Florinda Ferri Cintrão

Resumo: A preocupação com o desenvolvimento sustentável tem sido intensificada e se torna necessário buscar alternativas de produção baseadas na preservação dos recursos naturais, no cuidado com a saúde e na competitividade do pequeno agricultor. Com o objetivo de identificar as vantagens da produção orgânica para a agricultura familiar e os benefícios para o meio ambiente, foram formuladas as seguintes questões: quais as vantagens da produção orgânica como estratégia sustentável competitiva para a agricultura familiar e os benefícios da agricultura orgânica para o meio ambiente? Além disso, a presente pesquisa tem como objetivos específicos verificar as dificuldades encontradas pela agricultura familiar na produção de orgânicos, identificar as exigências para produção de orgânicos e pesquisar alternativas de fortalecimento para o agricultor familiar na produção de orgânicos. Para tanto, foi realizada pesquisa bibliográfica sobre o conceito de produtos orgânicos, sua evolução e certificação. Além disso, foi pesquisada a relação entre a agricultura orgânica, a sustentabilidade e a agricultura familiar, bem como o comportamento do consumidor orgânico. Dentre os resultados, estão os benefícios proporcionados pelo

\footnotetext{
'Mestrando em Desenvolvimento Territorial e Meio ambiente - Universidade de Araraquara - Uniara - Araraquara/ Sp.E-mail clayrperon@yahoo.com.br

${ }^{2}$ Mestranda em Desenvolvimento Territorial e Meio ambiente - Universidade de Araraquara - Uniara - Araraquara Sp.E-mail: arquitetura.olmedo@gmail.com

${ }^{3}$ Doutorando em Desenvolvimento Territorial e Meio Ambiente - Universidade de Araraquara - Uniara Araraquara/Sp. E-mail: e-biodel@usp.br

${ }^{4}$ Mestrando em Desenvolvimento Territorial e Meio ambiente - Universidade de Araraquara - Uniara - Araraquara/ Sp. E-mail: e-flavio@scalconet.com.br

Sp. E-mail: e-flavio@scalconet.com.br
${ }^{5}$ Docente do Programa de Pós-Graduação Stricto Sensu em Desenvolvimento Territorial e Meio Ambiente Universidade de Araraquara - Uniara - Araraquara/Sp. E-mail: jcintrao.mestrado@uniara.com.br
} 
fato dos produtos orgânicos possuírem maior valor comercial em relação ao convencional, serem saudáveis e de elevado valor nutricional, o que gera vantagem competitiva frente aos produtos da agricultura convencional, além de contribuírem para a preservação dos recursos naturais, pois são isentos de agrotóxicos e, assim, contribuem para saúde do homem, dos animais e do meio ambiente. Dentre as dificuldades encontradas pelo agricultor familiar na produção de orgânicos, encontram-se as dificuldades financeiras no processo de conversão da agricultura convencional para a orgânica e acesso ao crédito; quanto às principais exigências, existe a necessidade de serem produzidos sem o uso de agrotóxicos e de certificação para a comercialização; e já com relação às alternativas de fortalecimento do agricultor familiar na produção de orgânicos, estão a criação de associações ou cooperativas e de marcas próprias.

Palavras-chave: Agricultura Orgânica; Sustentabilidade; Agricultura Familiar.

ABSTRACT: The concern for sustainable development has been intensified and becomes necessary to look for alternatives of production based on the preservation of the natural resources, the health care and the competitiveness of the small farmer. Aiming to identify the advantages of organic production for family farming and the benefits to the environment, the following questions were raised: what are the advantages of organic production as a sustainable competitive strategy for family agriculture and the benefits of organic agriculture for the environment? Also, the present research has as specific objectives to verify the difficulties encountered by family farms in the production of organic, to identify the requirements for organic production and to research alternatives of strengthening for the familiar farmer in organic production. For this, a bibliographic research was carried out on the concept of organic products, its evolution and certification. In addition, the relationship between organic agriculture, sustainability and family agriculture, as well as organic consumer behavior, was researched. Among the results are the benefits provided by the fact that organic products have a higher commercial value in relation to the conventional, are healthy and of high nutritional value, which generates a competitive advantage over the products of conventional agriculture, besides contributing to the preservation of resources because they are free of pesticides and thus contribute to human, animal and environmental health. Among the difficulties encountered by the family farmer in organic production are the financial difficulties in the conversion process from conventional to organic agriculture and access to credit; as regards the main requirements, there is a need to be produced without the use of pesticides and certification for the commercialization; and already regarding the alternatives of strengthening the family farmer in the production of organic, are the creation of associations or cooperatives and of own brands.

KEYwORDS: Organic agriculture; Sustainability; Family farming.

\section{INTRODUÇÃO}

A busca desenfreada por mais produtividade em um período de tempo menor tem ocasionado danos à fauna e causando supressão vegetal, além do empobrecimento dos solos e contaminação dos recursos hídricos.

A preocupação com a sustentabilidade faz parte das discussões que envolvem pilares econômico, social e ambiental. As práticas ligadas à agricultura foram radicalmente modificadas o longo do tempo, o que resultou em maior da produtividade, porém com diversos efeitos negativos como degradação e empobrecimento do solo, contaminação dos recursos hídricos e danos à saúde entre outros, devido ao uso crescente de insumos químicos.

Conforme afirma Gliessman (2009), o uso acentuado de agrotóxicos na agricultura, devido sua rápida incorporação e eficiência no alcance de resultados imediatos, tem se tornado um importante vilão da degradação dos recursos naturais nos últimos tempos. Além disso, tem contribuído para a redução da matéria orgânica causada pela de ausência de cobertura vegetal, para a compactação do solo ocasionada pelo trânsito repetitivo de máquinas, onde a perda da matéria orgânica diminui a fertilidade do solo, o que tem contribuído para o desequilíbrio e degradação da sua estrutura. Ainda segundo o autor, a produtividade futura tende a ficar comprometida devido às práticas da agricultura convencional para acelerar a produtividade do presente.

De acordo com Campanhola e Valarini (2001), há diversas vantagens para ao agricultor familiar com a prática da agricultura orgânica, pois os produtos orgânicos geram maior valor comercial em relação ao convencional e maior vida útil no período pós-colheita; além disso, possibilita a diversificação produtiva no estabelecimento; requer mais mão-de-obra, o que contribui para a geração de empregos; apresenta menor dependência de insumos externos; elimina o uso de agrotóxicos, o que contribui para reduzir os custos de produção. As questões que nortearam a pesquisa foram quais as 
vantagens da produção orgânica como estratégia sustentável competitiva para a agricultura familiar e os benefícios da agricultura orgânica para o meio ambiente? Para responder ao problema de estudo proposto, foi realizada pesquisa bibliográfica.

Este artigo tem como objetivo verificar as dificuldades encontradas pela agricultura familiar na produção de orgânicos, identificar as exigências para a sua produção e discutir alternativas de fortalecimento para o agricultor familiar na produção de orgânicos. Para tanto, foi realizada pesquisa bibliográfica sobre o conceito de produtos orgânicos, sua evolução e certificação. Além disso, foi pesquisada a relação entre a agricultura orgânica, a sustentabilidade e a agricultura familiar, bem como o comportamento do consumidor orgânico.

Quanto à estrutura, além desta introdução é apresentado o desenvolvimento do tema, com o desdobramento nos seguintes itens: conceitos da agricultura orgânica; a agricultura orgânica como prática sustentável; a agricultura orgânica como alternativa para os agricultores familiares e conceitos de consumidor orgânico e seu comportamento. Em seguida, são apresentadas as considerações finais e por fim as referências utilizadas na pesquisa.

\section{Produtos Orgânicos}

Para que um produto seja considerado orgânico, é necessário que o mesmo tenha todo seu o processo, desde a produção até a distribuição, conforme os procedimentos e exigências legais estabelecidos para tal classificação.

De acordo com Darolt (2007), os alimentos orgânicos são produzidos por meio de sistemas que não utilizam agrotóxicos, tais como inseticidas, herbicidas, fungicidas, nematicidas, e outros insumos artificiais tóxicos, como adubos químicos altamente solúveis, bem como, Organismos Geneticamente Modificados (OGM), transgênicos ou radiações ionizantes.

Assim, esses elementos são excluídos do processo de produção, transformação, armazenamento e transporte, privilegiando a preservação da saúde do homem, dos animais e do meio ambiente, com respeito ao trabalho humano.

Conforme Darolt (2007, p.9) para um alimento processado ser considerado orgânico e receber o selo de qualidade, é preciso que contenha pelo menos $95 \%$ de ingredientes originados da agricultura orgânica, que contempla a forma de preparo do solo, adubação, controle de pragas e doença, controle de mato, teor de nitrato na planta e efeitos no meio ambiente.
O MAPA (2018) complementa que os produtos orgânicos devem ser cultivados sem o uso de agrotóxicos, adubos químicos e outras substâncias tóxicas e sintéticas. O objetivo é evitar a contaminação dos alimentos ou do meio ambiente. O resultado desse processo são produtos mais saudáveis, nutritivos e com mais qualidade de produção, preservando meio ambiente e a saúde das pessoas. Assim, a agricultura orgânica busca criar ecossistemas mais equilibrados, preservar a biodiversidade, os ciclos e as atividades biológicas do solo. Esta é a razão pela qual o agricultor orgânico não deve cultivar produtos transgênicos, para não colocar em risco a diversidade de variedades que existem na natureza.

Para tanto, é necessário cumprir todas as exigências da Lei n. 10.831, criada em 23 de dezembro de 2003, que estabelece as normas de produção, embalagem, distribuição e rotulagem para os produtos orgânicos de origem animal e vegetal, que conforme seu Art. $1^{\circ}$ :

Considera-se sistema orgânico de produção agropecuária todo aquele em que se adotam técnicas específicas, mediante a otimização do uso dos recursos naturais e socioeconômicos disponíveis e o respeito à integridade cultural das comunidades rurais, tendo por objetivo a sustentabilidade econômica e ecológica, a maximização dos benefícios sociais, a minimização da dependência de energia não renovável, empregando, sempre que possível, métodos culturais, biológicos e mecânicos, em contraposição ao uso de materiais sintéticos, a eliminação do uso de organismos geneticamente modificados e radiações ionizantes, em qualquer fase do processo de produção, processamento, armazenamento, distribuição e comercialização, e a proteção do meio ambiente.

Assim, cabe aos produtores de alimentos orgânicos, provenientes da agricultura ou pecuária, a responsabilidade de cumprir as exigências préestabelecidas. Já aos consumidores cabe a responsabilidade de conferir se os mesmos realmente são orgânicos, ou seja, verificar a origem dos produtos, a idoneidade da empresa produtora e existência do selo de certificação de alimentos orgânicos.

Os princípios da agricultura orgânica foram introduzidos no Brasil no início da década de 1970, quando surgiu a necessidade de se repensar o modelo convencional de produção agropecuária. Nos anos de 1972 e 1973, duas experiências de cunho prático surgem quase que simultaneamente e marcam o lançamento da semente orgânica no país. De 1973 a 1995, o 
desenvolvimento da agricultura orgânica ocorreu de forma muito lenta em todo país, passando por diversas etapas ligadas a contextos socioeconômicos e movimentos de ideias contrárias à agricultura convencional (DAROLT, 2007).

A partir do crescimento dos conceitos de benefícios à saúde humana $\mathrm{e}$ preservação do meio ambiente, as práticas de produção orgânica também conquistaram espaço no mercado de produção agrícola e pecuário.

De acordo com o SEBRAE (2017), o Brasil possui mais de $15 \mathrm{mil}$ propriedades certificadas e em processo de transição, dos quais $75 \%$ são agricultores familiares. O país está se consolidando como um grande produtor e exportador de alimentos orgânicos e a produção orgânica nacional está crescendo mais de $20 \%$ ao ano. Outra informação importante é que, mesmo com esse bom crescimento anual, é inferior à demanda pelos produtos, e ainda acaba se agravando, pois $70 \%$ da produção são exportados para a Europa.

O Ministério da Agricultura, Pecuária e Abastecimento (MAPA) é o órgão do governo federal responsável pela gestão das políticas públicas de estímulo à agropecuária, pelo fomento do agronegócio e pela regulação e normatização de serviços vinculados ao setor.

De acordo com a Lei $\mathrm{n}^{\circ} 10.831$, criada em 23 de dezembro de 2003, para a comercialização, os produtos orgânicos devem ser certificados por organismo reconhecido oficialmente, porém, em caso de comercialização direta aos consumidores, por parte dos agricultores familiares, inseridos em processos próprios de organização e controle social, previamente cadastrados junto ao órgão fiscalizador, a certificação será facultativa, uma vez assegurada aos consumidores e ao órgão fiscalizador a rastreabilidade do produto e o livre acesso aos locais de produção ou processamento.

De acordo com o MAPA (2018), o produtor que se cadastra apenas para venda direta e opta por trabalhar sem certificação, não pode realizar a vender para terceiros, somente em feiras, direto ao consumidor e para as compras do governo. Já quando o produto é certificado, o produtor pode vender seu produto em feiras, para supermercados, para lojas, para restaurantes, para hotéis, para indústrias, através da internet, entre outros.

A Lei $n^{\circ} 10.831 / 2003$ também define a finalidade de um sistema de produção orgânico como sendo a oferta de produtos saudáveis isentos de contaminantes intencionais; a preservação da diversidade biológica dos ecossistemas naturais e a recomposição ou incremento da diversidade biológica dos ecossistemas modificados em que se insere o sistema de produção; incrementar a atividade biológica do solo; promover um uso saudável do solo, da água e do ar, e reduzir ao mínimo todas as formas de contaminação desses elementos que possam resultar das práticas agrícolas; manter ou incrementar a fertilidade do solo no longo prazo; a reciclagem de resíduos de origem orgânica, reduzindo ao mínimo o emprego de recursos não-renováveis; basear-se em recursos renováveis e em sistemas agrícolas organizados localmente; incentivar a integração entre os diferentes segmentos da cadeia produtiva e de consumo de produtos orgânicos e a regionalização da produção e comércio desses produtos; e manipular os produtos agrícolas com base no uso de métodos de elaboração cuidadosos, com o propósito de manter a integridade orgânica e as qualidades vitais do produto em todas as etapas.

A certificação dos produtos orgânicos é realizada por instituições certificadoras e existem também associações responsáveis pelo acompanhamento e fiscalização desse tipo de produção.

De acordo com Darolt (2007) a certificação é um processo de inspeção das propriedades agrícolas, para verificar se o alimento orgânico está sendo cultivado e processado de acordo com as normas de produção orgânica. A inspeção tem como foco a terra e o processo de produção, e não o produto em si. Assim, uma vez credenciada, a propriedade pode gerar vários produtos certificados, que irão receber um selo de qualidade.

Para Camponhola e Valarini (2001), a certificação de produtos orgânicos visa proporcionar maior credibilidade aos consumidores e conferir maior transparência às práticas e aos princípios utilizados na produção orgânica, além de ser necessária para obtenção de crédito. Porém, em função da diversidade da rede de produção orgânica brasileira, foram regulamentados três mecanismos de controle para a garantia da qualidade orgânica:

- Certificação por Auditoria - neste mecanismo as certificadoras públicas ou privadas credenciadas pelo MAPA utilizam os procedimentos e critérios reconhecidos internacionalmente para organismos de avaliação da conformidade, acrescidos dos requisitos técnicos estabelecidos pela legislação brasileira para a agricultura orgânica. A certificação por auditoria exige que a avaliação da conformidade seja feita por uma certificadora independente, sem vínculo direto com quem produz ou com quem compra. A certificadora credenciada pelo MAPA, ao aprovar a certificação de um produtor, fica responsável por incluí-lo no Cadastro Nacional de Produtores Orgânicos e a 
autorizá-lo a utilizar o selo do SisOrg;

- Sistemas Participativos de Garantia (SPG) - caracterizamse pela responsabilidade coletiva de seus membros, que podem ser produtores, consumidores, técnicos e quem mais se interesse em fortalecer esses sistemas. Os métodos de geração de credibilidade são adequados a diferentes realidades sociais, culturais, políticas, territoriais, institucionais, organizacionais e econômicas. O SPG tem que possuir um Organismo Participativo de Avaliação da Conformidade (OPAC), legalmente constituído e credenciado pelo MAPA, cuja responsabilidade é avaliar a conformidade orgânica dos produtos, incluir os produtores orgânicos no Cadastro Nacional de Produtores Orgânicos e autorizá-los a utilizar o selo do SisOrg;

- Controle social na venda direta - a legislação brasileira abriu uma exceção na obrigatoriedade de certificação dos produtos orgânicos que são vendidos diretamente aos consumidores, em feiras e pequenos mercados locais, por exemplo. Para isso, os produtores têm que fazer parte de uma Organização de Controle Social (OCS) cadastrada no Ministério da Agricultura, Pecuária e Abastecimento ou em outro órgão fiscalizador federal, estadual ou distrital conveniado, que pode ser um grupo de agricultores familiares, associação, cooperativa ou consórcio, com ou sem personalidade jurídica. Dessa forma, os agricultores familiares passam a fazer parte do Cadastro Nacional de Produtores Orgânicos. Além disso, os agricultores terão de garantir a rastreabilidade de seus produtos e o livre acesso dos órgãos fiscalizadores e dos consumidores aos locais de produção e processamento. A OCS tem o papel de orientar os associados sobre a qualidade dos produtos orgânicos e, para que tenha credibilidade e seja reconhecida pela sociedade, precisa estabelecer uma relação de organização, comprometimento e confiança entre os participantes. Assim que a OCS estiver cadastrada, o órgão fiscalizador emiti um documento, chamado de Declaração de Cadastro, para cada produtor vinculado a ela.
Esse documento deve estar disponível no momento da venda direta de produtos orgânicos para os consumidores.

A partir de janeiro de 2011, todos os produtos comercializados como orgânicos passaram a conter o selo do Sistema Brasileiro de Conformidade Orgânica como exigência comercial. No entanto, para venda direta ao consumidor, no ponto de comercialização ou no rótulo dos produtos, poderá constar a seguinte expressão: "produto orgânico não sujeito à certificação nos termos da Lei nํㅡㄴ 10.831, de 23 de dezembro de 2003” (BRASIL, 2003).

De acordo com o MAPA (2018), para utilizar o selo do Sistema Brasileiro de Avaliação da Conformidade Orgânica, os produtos comercializados diretamente aos consumidores, devem ser verificados por organismo de avaliação da conformidade credenciado junto ao Ministério da Agricultura, Pecuária e Abastecimento.

Dessa forma, não há a exigência de certificação de produtos orgânicos para a comercialização direta ao consumidor. A certificação se torna obrigatória para comercializar os produtos orgânicos com estabelecimentos comerciais como supermercados, hotéis e restaurantes.

\section{A RELAÇÃo ENTRE A AGRICULTURA ORGÂNICA E A SUSTENTABILIDADE}

A grande mudança nas atividades agropecuárias ocorreu a partir da década de 1960 com a chamada Revolução Verde, pois métodos de produção considerados inovadores começaram a ser utilizados. $\mathrm{Na}$ agricultura, em especial, as lavouras passaram a ser mecanizadas, além da utilização intensiva de fertilizantes e agrotóxicos.

De acordo com Miller (2008), a Revolução Verde trouxe um pacote tecnológico, com o uso de máquinas, insumos industriais e outras técnicas o que provocou, junto com o aumento dos índices de produção, o aumento da utilização dos insumos para controlar as pragas, do cultivo do solo, da monocultura, da irrigação, o que acarretou problemas para a saúde e desequilíbrios naturais provocados pela excessiva extração dos recursos.

Em busca de maior produtividade, alguns impactos foram identificados no campo social, econômico e ambiental. Conforme afirma Motta (2002), sob a ótica social, a Revolução Verde promoveu um enorme êxodo rural, ocasionado pela modernização do meio rural (mecanização do campo) e acentuada concentração de terras. Já sob a ótica econômica, devidos aos recursos empregados na modernização agrícola, foi instaurado o endividamento externo da economia brasileira ao final dos anos 1970, e a 
concentração de renda na mão de poucos gerou maior pobreza. E quanto ao aspecto ambiental, a agropecuária começou a ser responsável também pelo agravamento de questões ambientais referentes à contaminação do solo e dos mananciais de água, à erosão do solo, à diminuição da biodiversidade, ao aquecimento global, à salinização do solo, ao assoreamento dos rios, aos processos de compactação do solo e à perda de matéria orgânica.

É inegável que as inovações agropecuárias trouxeram um aumento na produtividade, porém os reflexos desse aumento foram danosos ao desenvolvimento sustentável, visto que os impactos sociais, econômicos e ambientais podem ser sentidos desde então até os dias atuais.

De acordo com Primavesi (2003), a Revolução Verde foi responsável por abrir a agricultura para a indústria, e como consequência, propiciar o início do desmatamento e da exploração dos solos no mundo inteiro.

Ainda de acordo com a autora, a agricultura convencional está causando sérios danos aos solos, à água e ao ar, à saúde vegetal e à humana. Dentre os problemas trazidos pela Revolução Verde, merecem destaque a poluição da estratosfera, que causa o aumento do efeito estufa, e a compactação do solo, além da erosão, das enchentes, das tempestades de poeira e das secas que apareceram juntamente com a adoção das novas tecnologias.

A preocupação com o desenvolvimento sustentável tem sido intensificada, e de acordo com May, Lustosa e Vinha (2003), é possível desenvolver um ecossistema agrícola com base em sistemas de produção que possibilitem a preservação de mecanismos básicos de regulação ecológica, como a manutenção da fertilidade do solo através de processos naturais de reciclagem de nutrientes e da rotação de culturas.

Diante dos danos causados ao meio ambiente e seus efeitos à saúde pela agricultura convencional, e a necessidade de reversão desse quadro de degradação e escassez dos recursos naturais, encontramos a opção da agricultura orgânica.

Conforme afirmam Buainain e Batalha (2007), o produtos orgânicos, tanto de origem animal ou como vegetal, são livres da presença de agrotóxicos ou qualquer outro tipo de produto químico e o seu cultivo e as suas práticas devem estabelecer o equilíbrio ecológico do sistema agrícola.

Dessa forma, a produção orgânica é um sistema que visa se aproximar da natureza e da qual é eliminada a utilização de produtos químicos. Nesse sistema, é dada prioridade à utilização de recursos naturais.

Segundo o MAPA (2018), os produtos orgânicos são produzidos sem causar prejuízos ao meio ambiente e de forma a preservar os recursos naturais. Dessa forma, visa a evitar a destruição ou o desgaste do solo, e tem como objetivo protegê-lo ou recuperá-lo para que mantenha sua fertilidade. A agricultura orgânica não utiliza elementos transgênicos, pois evita colocar em risco a diversidade de variedades presentes na natureza. $\mathrm{Na}$ agricultura orgânica, é proibida a utilização de agrotóxicos e outras substâncias sintéticas prejudiciais ao alimento ou ao meio ambiente.

No Quadro 1, apresentam-se as diferenças de sistemas de produção de alimentos, um comparativo entre produtos convencionais e produtos orgânicos de acordo com Darolt (2007):

Quadro 1 - Diferenças entre as formas de produção de alimentos.

\begin{tabular}{|c|c|c|}
\hline \multirow[b]{2}{*}{ Características } & \multicolumn{2}{|c|}{ Sistema de produção } \\
\hline & Convencional & Orgânico \\
\hline Preparo do solo & $\begin{array}{l}\text { Intensamente revolvido, per- } \\
\text { turbando a vida do solo }\end{array}$ & $\begin{array}{l}\text { O solo é considera- } \\
\text { do um organismo } \\
\text { vivo e deve ser re- } \\
\text { volvido o mínimo } \\
\text { possível }\end{array}$ \\
\hline Adubação & $\begin{array}{l}\text { Uso de adubos químicos alta- } \\
\text { mente solúveis: ureia, NPK, } \\
\text { entre outros }\end{array}$ & $\begin{array}{l}\text { Uso de adubos or- } \\
\text { gânicos de baixa } \\
\text { solubilidade }\end{array}$ \\
\hline Controle de pragas e doenças & $\begin{array}{l}\text { Uso de produtos químicos: in- } \\
\text { seticidas, fungicidas, bacterici- } \\
\text { das }\end{array}$ & $\begin{array}{l}\text { Controle com me- } \\
\text { didas preventivas e } \\
\text { produtos naturais }\end{array}$ \\
\hline Controle do mato & $\begin{array}{l}\text { Mato é considerado uma erva } \\
\text { daninha e deve ser eliminado. } \\
\text { Uso de herbicidas, controle } \\
\text { mecânico ou manual }\end{array}$ & $\begin{array}{l}\text { O mato faz parte do } \\
\text { sistema: pode ser } \\
\text { usado como cober- } \\
\text { tura de solo e abrigo } \\
\text { de insetos. O con- } \\
\text { trole é preventivo: } \\
\text { manual ou mecâni- } \\
\text { co (roçadas) }\end{array}$ \\
\hline Teor de nitrato na planta & Médio & Baixo \\
\hline Efeitos no meio ambiente & $\begin{array}{l}\text { Poluição das águas e degrada- } \\
\text { ção do solo }\end{array}$ & $\begin{array}{l}\text { Preservação do solo } \\
\text { e das fontes de água }\end{array}$ \\
\hline
\end{tabular}

Fonte: Darolt (2007). 
Dessa forma, os produtos da agricultura orgânica, sejam in natura ou processados, são todos aqueles obtidos através de normas e princípios específicos para produção agropecuária e/ou industrial orgânica.

Conforme afirma Darolt (2007), os diferenciais da agricultura orgânica estão presentes na forma de produção se comparada à agricultura convencional. Conforme o Quadro 1, as primeiras diferenças aparecem no preparo do solo, na qual a agricultura orgânica busca preservar o solo e o considera como um organismo vivo. Quanto à adubação, verifica-se mais um grande diferencial da agricultura orgânica que utiliza somente adubos orgânicos de baixa solubilidade, em detrimento ao uso de adubos químicos. Já com relação ao controle de pragas e doenças, mais diferenciais são encontrados, pois utiliza produtos naturais e medidas preventivas, ao invés de produtos químicos como inseticidas, fungicidas e bactericidas. Outros diferenciais também a se destacar, são os efeitos proporcionados ao meio ambiente, estão na busca pela preservação do solo e das fontes de água.

Diante dessas informações, são evidentes os benefícios proporcionados pelo sistema de produção orgânico, quando comprados com o sistema de produção convencional, ao meio ambiente no que se refere ao uso de produtos químicos, à preservação da água, do solo e de recursos naturais, com consequentes benefícios ao consumidor final.

A relaÇão entre a ProduÇão ORgâniCa E A AGRICULTURA FAMILIAR

A produção orgânica ganha importância e pode ser uma diferencial para a agricultura familiar. Conforme afirmam Camponhola e Valarini (2001), devido à crescente demanda mundial por alimentos mais saudáveis, a agricultura orgânica se destaca como uma das alternativas de renda para os pequenos agricultores.

De acordo com o MAPA (2018), a agricultura familiar tem um papel muito importante na preservação do meio ambiente. Atualmente, existem 12 mil produtores de orgânicos no Brasil e, desse total, 70\% são agricultores familiares.

De acordo com Camponhola e Valarini (2001), cinco são os motivos para que se tenham boas perspectivas com relação aos pequenos agricultores na inserção da agroecologia:

1) em primeiro lugar, está o fato de as commodities agrícolas convencionais necessitarem de alta escala de produção para compensar tanto a queda estrutural de preços, que vem ocorrendo nas últimas três décadas, como o aumento crescente dos custos de produção e a redução das margens de lucro, o que dificulta a concorrência para o produtor de pequenas quantidades. Em contra partida, na agricultura orgânica, o produtor consegue trabalhar com escala menor de produção, pois o diferencial do produto está em suas características, não no preço somente;

2) o segundo motivo é que os produtos orgânicos têm como foco atingir nichos de mercado e, dessa forma, visam a atender a um segmento restrito e seleto de consumidores, que, diferentemente do que acontece com as commodities agrícolas, estão dispostos a pagar um preço maior pelas características e benefícios desses produtos. Assim, os pequenos produtores e agricultores familiares, apesar de uma baixa escala produtiva, podem utilizar a estratégia local de distribuição e disponibilizar seus produtos em pequenos mercados locais. Com esta estratégia, o pequeno agricultor promove a interação com os consumidores e possibilita adequar seus produtos conforme as exigências, fortalece as relações de confiança e de credibilidade entre as partes envolvidas;

3) em terceiro lugar, os autores referem-se à possibilidade dos pequenos agricultores serem incluídos nas redes nacionais ou transnacionais de comercialização de produtos orgânicos. Para essa inserção seja facilitada, os produtores devem se organizar em associações ou em cooperativas, devido aos benefícios trazidos por essas formas de organização, como por exemplo, maior facilidade das ações de marketing e de implantação de selos de qualidade, maior poder de negociação nas operações de venda e maior capacidade de gestão das atividades produtivas.

4) o quarto motivo refere-se ao fato de os produtos orgânicos como as hortaliças e as plantas medicinais serem, historicamente, produzidos por pequenos agricultores e não despertarem o interesse dos grandes empreendedores agropecuários;

5) já o quinto motivo trata da diversificação da produção orgânica e do fato de diminuir a dependência de insumos externos ao estabelecimento. Isso gera uma vantagem ao pequeno agricultor em relação aos demais grupos de produtores. A diversificação da produção 
possibilita ao pequeno agricultor a vantagem de ter estabilidade na renda durante o ano, pois diminui a influência da sazonalidade, e melhora segurança do agricultor, devido à redução o risco de quebras na renda provocadas pela flutuação nos preços e a incidentes naturais. Com relação à menor dependência de insumos externos, se justifica pela menor área cultivada pelos pequenos agricultores e também pela maior facilidade de manejo dos sistemas produtivos com recursos da própria propriedade, como por exemplo, os fertilizantes orgânicos, os produtos naturais para controle fitossanitário, o controle biológico natural, a tração animal, os combustíveis não fósseis, etc.

Estrategicamente falando, os sistemas de produção orgânica se apresentam como uma grande oportunidade aos pequenos agricultores, pois, apesar de utilizarem mais mão de obra e apresentarem menor produtividade que os sistemas convencionais, apresentam um desempenho econômico melhor, devidos aos menores custos efetivos, às maiores relações custo-benefício e às maiores rendas efetivas.

Conforme afirma Wilkinson (2000), outro fator a se destacar como vantagem estratégica para o pequeno agricultor orgânico frente à agricultura convencional é o fator de ser lembrado como natural. A agricultura familiar apresenta uma vantagem estratégica na medida em que é associada à tradição, à natureza, ao artesanato, ao local - um conjunto de valores que atualmente passa a ser premiado pelo mercado. Esses valores incluem a superioridade de atividades artesanais e a preservação do meio ambiente em todas as suas múltiplas formas e biodiversidade se comparados ao modelo de produção convencional.

Nos dias atuais, há uma valorização dos produtos naturais, que proporcionam maior qualidade de vida e saúde e que não agridem ou causem danos ao meio ambiente. Assim, esses fatores passam a refletir pontos fortes que devem ser explorados pelos produtores orgânicos e serem utilizados como diferenciais competitivos frente aos produtos convencionais.

A prática de uma agricultura ecológica e sustentável passa a ser a nova estratégia de mercado para o pequeno a produtor e vai ao encontro das exigências e preocupações que parte do mercado consumidor atualmente apresenta. Isso se justifica pelas críticas ao modelo de agricultura que se embasa no uso indiscriminado de agrotóxicos na produção de alimentos para busca de uma maior produtividade.

De acordo com Martins (2012), o Ministério da Agricultura, Pecuária e Abastecimento (MAPA) afirma que a agricultura orgânica ou ecológica apresenta as seguintes vantagens:

- oferta produtos saudáveis e que possuem um elevado valor nutricional, isentos de qualquer tipo de contaminantes que coloque em risco a saúde do consumidor, do agricultor e cause danos ao meio ambiente;

- preserva e amplia a biodiversidade dos ecossistemas, natural ou transformado, no qual o sistema produtivo esteja inserido;

- conserva as condições químicas, biológicas e físicas do solo, da água e do ar;

- fomenta da integração efetiva entre agricultor e consumidor final de produtos orgânicos;

- incentiva à regionalização da produção orgânica para os mercados locais.

A produção orgânica se projeta como uma grande oportunidade de mercado para os pequenos agricultores de caráter familiar, pois é viável em áreas pequenas e com baixa escala de produção; possibilita a diversificação produtiva no estabelecimento; necessita de mais mão-de-obra, o que gera mais empregos, em detrimento ao processo de modernização da agricultura convencional; possui menor dependência de insumos externos; é isenta do uso de agrotóxicos e apresenta maior biodiversidade do solo; possui maior valor comercial em relação aos produtos convencionais e adoção mais fácil para os produtores que ainda não utilizam as tecnologias da agricultura convencional, devido ao fato de não precisarem se desfazer dos insumos, máquinas e equipamentos adquiridos que não serão utilizados na produção orgânica, além de não terem problemas com resíduos de agrotóxicos no solo, pois isso exigiria um maior período de tempo para a sua descontaminação natural, o que facilita obter a certificação orgânica de seus produtos em um tempo mais rápido.

De acordo com Beltrão apud Harkaly (1999), os pequenos produtores e os agricultores familiares, devido à necessidade de diversificação da produção, possuem maior facilidade de adaptação aos princípios da agricultura orgânica. Os princípios apontados pelo autor correspondem à diversificação, à integração da propriedade, à indução do equilíbrio ecológico, à reciclagem de nutrientes, aos insumos caseiros, à conservação do solo e ao controle de pragas e de doenças de maneira ecológica.

Porém, de acordo com Buainain e Batalha (2007), apesar de a produção 
orgânica ser mais adequada à realidade de sistemas de produção familiares, alguns fatores como custos de conversão e certificação aparecem como obstáculos significativos para o ingresso de pequenos produtores e agricultores familiares na atividade e ainda um entrave para a sua permanência no sistema de produção orgânico.

É importante ressaltar as dificuldades encontradas pelo pequeno agricultor orgânico. No Quadro 2, apresentam-se alguns dos problemas afirmados por Campanhola e Valarini (2001):

Quadro 2 - Dificuldades encontradas pelo pequeno agricultor orgânico.

\begin{tabular}{|c|c|}
\hline Dificuldades & Causa e/ou Consequências \\
\hline $\begin{array}{l}\text { Pequena escala de produ- } \\
\text { ção }\end{array}$ & $\begin{array}{l}\text { O pequeno volume produzido, somado a irregularidade na oferta de } \\
\text { produtos durante o ano, dificultam a negociação com distribuidores } \\
\text { e varejistas e o estabelecimento de contratos mais duradouros e } \\
\text { vantajosos ao pequeno agricultor. }\end{array}$ \\
\hline $\begin{array}{l}\text { Instabilidade devido à bai- } \\
\text { xa capacitação gerencial }\end{array}$ & $\begin{array}{l}\text { Deficiências na capacitação e na visão gerencial dificultam a } \\
\text { gestão técnica e financeira do empreendimento por parte dos } \\
\text { pequenos produtores rurais e agricultores familiares, como também } \\
\text { os colocam em desvantagem no processo de comercialização da } \\
\text { produção. }\end{array}$ \\
\hline $\begin{array}{l}\text { Escassez de pesquisa cien- } \\
\text { tífica em agricultura orgâ- } \\
\text { nica }\end{array}$ & $\begin{array}{l}\text { Há carência de atuação das instituições públicas no desenvolvimento } \\
\text { e/ou validação de tecnologias de produção orgânica, e isso gera } \\
\text { prejuízos aos pequenos agricultores, pois, geralmente, não têm } \\
\text { acesso a informações que poderiam ser utilizadas de forma } \\
\text { experimental em suas lavouras e agem por tentativas empíricas que } \\
\text { acabam resultando em erros e acertos. }\end{array}$ \\
\hline $\begin{array}{l}\text { Carência de assistência } \\
\text { técnica pública }\end{array}$ & $\begin{array}{l}\text { As dificuldades de acesso à assistência técnica pública sempre } \\
\text { foi uma realidade para os pequenos produtores e agricultores } \\
\text { familiares. No caso da agricultura orgânica, o problema é ainda } \\
\text { maior, pois, em geral, a rede pública não está preparada para prestar } \\
\text { assistência técnica em agricultura orgânica. Assim, os pequenos } \\
\text { agricultores acabam tendo que contratar consultores privados ou } \\
\text { técnicos de ONGs que atuam no ramo, e isso gera aumento dos seus } \\
\text { custos de produção. }\end{array}$ \\
\hline $\begin{array}{l}\text { Maior necessidade de mão } \\
\text { de obra }\end{array}$ & $\begin{array}{l}\text { A agricultura orgânica necessita de uma maior quantidade de mão } \\
\text { de obra por unidade de área que a agricultura convencional. Dessa } \\
\text { forma, os pequenos agricultores acabam tendo uma sobrecarga } \\
\text { de trabalho, que inclui os membros de sua família, e também, em } \\
\text { algumas etapas do ciclo produtivo, acabam recorrendo à contratação } \\
\text { de mão de obra externa ao estabelecimento, mão de obra essa que } \\
\text { às vezes não está disponível ou não é capacitada para a agricultura } \\
\text { orgânica, o que torna inviável a prática da produção orgânica em } \\
\text { algumas localidades. }\end{array}$ \\
\hline
\end{tabular}

Quadro 2 - Dificuldades encontradas pelo pequeno agricultor orgânico. (Cont.)

\begin{tabular}{|c|c|}
\hline $\begin{array}{l}\text { Dificuldades financeiras } \\
\text { no processo de conversão } \\
\text { da agricultura convencio- } \\
\text { nal em agricultura orgâni- } \\
\text { ca }\end{array}$ & $\begin{array}{l}\text { Esse processo exige recursos financeiros no início e os custos } \\
\text { variam para cada situação. Os custos referem-se à aquisição de } \\
\text { implementos e materiais adequados, à aquisição de animais e } \\
\text { sementes, à introdução de práticas de preparo e conservação do } \\
\text { solo, à adaptação da infraestrutura produtiva, à assistência técnica, } \\
\text { entre outras. Um grande problema ocorre porque as instituições } \\
\text { financeiras, que possuem linha de crédito para produção orgânica, } \\
\text { exigem certificação como pré-requisito para obtenção de crédito. } \\
\text { Assim, a entrada de novos pequenos agricultores na atividade fica } \\
\text { prejudicada, pois o processo de conversão e certificação leva pelo } \\
\text { menos dois anos. }\end{array}$ \\
\hline $\begin{array}{l}\text { Custos de certificação e de } \\
\text { acompanhamento das exi- } \\
\text { gências da certificação }\end{array}$ & $\begin{array}{l}\text { Esses custos referem à taxa de certificação cobrada pelas } \\
\text { organizações certificadoras, às despesas para que sejam realizadas } \\
\text { as visitas periódicas de fiscalização e à assistência técnica } \\
\text { periódica que podem ser necessárias. A soma desses pagamentos } \\
\text { contribui para elevar os seus custos de produção. Porém, no caso } \\
\text { da comercialização direta aos consumidores, a certificação é } \\
\text { facultativa. }\end{array}$ \\
\hline $\begin{array}{l}\text { Dificuldade de processa- } \\
\text { mento dos produtos agro- } \\
\text { pecuários }\end{array}$ & $\begin{array}{l}\text { Para os pequenos agricultores torna-se mais difícil instalar, } \\
\text { individualmente, uma estrutura de processamento dos produtos } \\
\text { devido à baixa escala de produção. Porém, o processamento } \\
\text { pode ser viabilizado se os pequenos agricultores se organizarem } \\
\text { por meio de associações ou cooperativas. Com o processamento, } \\
\text { os produtores passam a agregar valor aos produtos agropecuários } \\
\text { orgânicos. }\end{array}$ \\
\hline $\begin{array}{l}\text { Efeitos ambientais nega- } \\
\text { tivos }\end{array}$ & $\begin{array}{l}\text { Apesar de a agricultura orgânica ser considerada uma prática } \\
\text { ambientalmente correta, pode causar danos ambientais se conduzida } \\
\text { de forma errada, como os danos resultantes do uso de quantidade } \\
\text { excessiva de matéria orgânica no solo, que representa maior risco } \\
\text { de acumulação de nitratos nas águas subterrâneas; os efeitos dos } \\
\text { estercos de aves e suínos adicionados ao solo, pois o de aves pode } \\
\text { apresentar inconvenientes do ponto de vista da sanidade das plantas, } \\
\text { da perda de nutrientes minerais e dos danos, no médio prazo, às } \\
\text { condições físicas e biológicas do solo; enquanto que o esterco de } \\
\text { suínos pode conter gordura e transmitir doenças ao homem. }\end{array}$ \\
\hline
\end{tabular}

Fonte: Campanhola e Valarini (2001).

Diante dos obstáculos apresentados, torna-se necessário buscar alternativas para superá-los e para que os produtores orgânicos possam aproveitar essa oportunidade que o mercado apresenta.

De acordo com Campanhola e Valarini (2001), para que os pequenos agricultores aproveitem plenamente as novas oportunidades que o mercado 
oferece, dois grupos de ações são necessários e devem ser pautados nos princípios do desenvolvimento local ${ }^{6}$.

Segundo os autores, o primeiro grupo de ações de ser desenvolvido pelo poder público e suas instituições, e engloba as seguintes ações:

1) criar mecanismos para facilitar o acesso ao crédito de custeio e investimento para os pequenos agricultores, principalmente na etapa de conversão dos sistemas de produção convencionais em orgâni$\cos$.

2) ofertar apoio, por intermédio das instituições de pesquisa e desenvolvimento e daquelas de assistência técnica e extensão rural, no que se refere à geração e/ou adaptação de conhecimentos necessários à produção orgânica, no estímulo à mobilização dos pequenos agricultores visando a sua organização por meio de associações e cooperativas locais e na capacitação técnica e gerencial dos pequenos agricultores para a condução dos sistemas de produção orgânica e gestão adequada do seu empreendimento.

3) desenvolver uma política de incentivo e apoio à produção orgânica com foco nos pequenos agricultores, considerando principalmente as etapas de conversão aos sistemas orgânicos e de comercialização, além de integrá-la a outras políticas de desenvolvimento rural sustentável.

4) incentivar e fomentar a criação de pontos de venda de produtos orgânicos exclusivos para pequenos agricultores nos municípios.

5) apoiar a instalação de pequenas agroindústrias que agreguem pequenos agricultores para o processamento de seus produtos orgânicos através de medidas de incentivos monetários,

Já o segundo grupo de ações, de acordo com Campanhola e Valarini (2001), caberia à iniciativa dos pequenos agricultores com a finalidade de:

1) criar mecanismos para a organização local e para a implantação e/ ou fortalecimento de associações e cooperativas para que possa se

6 "Entende-se por "desenvolvimento local" o processo de tornar dinâmicas as vantagens comparativas e competitivas de uma determinada localidade, de modo a favorecer o crescimento econômico e simultaneamente elevar o capital humano, o capital social e o capital empresarial, bem como conquistar o uso sustentável do capital natural" (PAULA, 2008, p.11).

fortalecer.

2) ampliar os canais de comercialização direta de produtos orgânicos com o objetivo de atingir os consumidores e também os estabelecimentos do comércio local.

3) utilizar marcas comerciais próprias de alimentos orgânicos com a finalidade de fortalecer a credibilidade dessas marcas entre aos consumidores locais e buscar a sua fidelidade.

O mercado de produtos orgânicos apresenta grandes oportunidades para o pequeno produtor e para a agricultura familiar devido à preocupação com os danos causados pela agricultura convencional ao meio ambiente e à saúde. Para tanto, é necessário criar mecanismos para que esses produtores possam aproveitar essas oportunidade e se tornarem competitivos.

\section{CONSUMIDOR ORGÂNICO}

Com relação ao comportamento do consumidor, é importante destacar a preocupação com a saúde e com a sustentabilidade. Isso também apresentada uma ameaça para as empresas que não são ecologicamente responsáveis.

De acordo com Ottman (2012, p. 65);

Os consumidores têm procurado controlar um mundo que eles veem fora de controle. Levados a proteger a própria saúde e de sua família os consumidores preocupados com a sustentabilidade assumem controle no mercado, analisando produtos e suas embalagens e ingredientes com muita atenção: como precação, eles também analisam a reputação de fabricantes de produtos para ver se têm responsabilidade social e ecológica.

Dessa forma, observa-se que a cada vez mais as pessoas estão buscando alternativas para que se possa melhorar a qualidade de vida e preservar do meio ambiente. Esses fatores geram maior demanda, que impulsionam o crescimento da produção e comercialização de produtos orgânicos.

Conforme afirma Dias (2011), o comportamento do consumidor ambientalmente consciente, ao adquirir gradativamente um novo modelo de paradigma de consumo, leva as empresas a adotar uma nova postura com relação ao marketing, uma postura que passa a considerar os aspectos ecológicos. 
Ainda de acordo com Dias (2011), o novo consumidor ecológico reflete no seu comportamento de compra as suas preocupações ambientais. Nessa nova postura, o consumidor ecológico busca produtos que considera causar menos impactos negativos ao meio ambiente e valoriza aqueles que são produzidos por empresas que são ambientalmente responsáveis. Dessa forma, assumem que podem pagar um preço mais alto pelo produto ecologicamente correto, $\mathrm{e}$ compreendem que o valor agregado, mesmo com um aumento no seu preço final, significa um aumento no seu valor social.

De acordo com Dulley (2003), o Ministério da Agricultura Norte Americano (USDA) afirma que além dos benefícios proporcionados pela produção orgânica ao meio ambiente, existem pesquisas que apontam que os consumidores estão dispostos a pagar mais para obter a qualidade orgânica agregada ao produto, pelo fato de se preocupar com a saúde de sua família.

Os consumidores ecológicos estão engajados na causa ambiental e têm preferência por produtos considerados ecologicamente corretos. Esses consumidores, além da consciência ambiental, estão cientes de que a produção pautada por atividades sustentáveis possuem maior custo e estão dispostos a pagar mais por esse produto ou serviço, pois entendem a elevação do preço devido às questões ambientais envolvidas.

\section{ConClusão}

Atualmente, os pequenos proprietários rurais e os agricultores familiares têm na agricultura orgânica a possibilidade utilizar uma estratégia para promover o seu desenvolvimento econômico e social, agregar valor aos seus produtos e contribuir para o desenvolvimento sustentável do planeta.

A questão que norteou a pesquisa foi identificar quais as vantagens da produção orgânica como estratégia sustentável competitiva para a agricultura familiar. Dessa forma, foi identificado que os seguintes benefícios: os produtos orgânicos atendem a um nicho restrito de mercado, o que permite trabalhar mesmo com baixa escala de produção para atender os mercados locais; possui maior valor comercial em relação ao convencional e maior vida útil no período pós-colheita. Outros benefícios são a diversificação da produção orgânica, a diminuição da dependência de insumos externos ao estabelecimento e a oferta produtos saudáveis e de elevado valor nutricional em detrimento às críticas ao modelo de agricultura que se embasa no uso indiscriminado de agrotóxicos na produção de alimentos para busca de uma maior produtividade.

Com relação aos benefícios da agricultura orgânica para o meio ambiente, identificou-se que os produtos orgânicos são isentos de qualquer tipo de contaminantes que ponham em risco a saúde do consumidor, do agricultor e do meio ambiente; preserva e amplia a biodiversidade dos ecossistemas, natural ou transformado, em que se insere o sistema produtivo e conserva as condições físicas, químicas e biológicas do solo, da água e do ar.

No entanto, algumas dificuldades e obstáculos se encontram no caminho dos pequenos agricultores, como a pequena escala de produção somada a irregularidade na oferta de produtos durante o ano, que dificultam a negociação com distribuidores e varejistas e o estabelecimento de contratos mais duradouros e vantajosos ao pequeno agricultor; a instabilidade devido à baixa capacitação gerencial; escassez de pesquisa científica em agricultura orgânica; a carência de assistência técnica da rede pública; a maior necessidade de mão de obra; as dificuldades financeiras encontradas durante o processo de conversão da agricultura convencional para a orgânica; as dificuldades de acesso ao crédito bancário; os custos de certificação (garantia do selo orgânico) e de acompanhamento das exigências da certificação; a dificuldade de processamento dos produtos agropecuários e os efeitos ambientais negativos, caso a agricultura orgânica seja conduzida de forma errada.

Quanto ás exigências para a produção de orgânicos, é necessário atender as normativas da lei $\mathrm{N}^{\mathrm{o}} 10.831 / 2003 \mathrm{e}$, para a comercialização, os produtos orgânicos devem ser certificados por organismo reconhecido oficialmente.

Algumas ações se tornam necessárias para que o pequeno agricultor possa entrar, permanecer e se tornar competitivo no mercado orgânico como a criação, por parte do poder público e suas instituições, de mecanismos que facilitem o acesso dos pequenos agricultores ao crédito de custeio e investimento, principalmente na etapa de conversão dos sistemas de produção convencionais em orgânicos; apoio, por intermédio das instituições de pesquisa e desenvolvimento e daquelas de assistência técnica e extensão rural; desenvolvimento de uma política de incentivo e apoio à produção orgânica direcionada aos pequenos agricultores; incentivo à criação de pontos de venda de produtos orgânicos nos municípios, que atendam exclusivamente aos pequenos agricultores; e apoio, através de medidas de incentivos monetários, à instalação de pequenas agroindústrias que agreguem pequenos agricultores para o processamento de seus produtos orgânicos.

Outras ações, por parte dos próprios produtos, devem ser utilizadas, visando maior competitividade no mercado, como a criação de mecanismos para a organização local e para a implantação e/ou fortalecimento de associações e cooperativas para que possa se fortalecer; a ampliação 
dos canais de comercialização direta de produtos orgânicos visando tanto os consumidores, como os estabelecimentos do comércio local e a utilização de marcas comerciais próprias de alimentos orgânicos para fortalecer a credibilidade dessas marcas entre aos consumidores locais, buscando a sua fidelidade na compra desses produtos.

\section{REFERÊNCIAS}

BRASIL. Lei 10.831 de 23 de dezembro de 2003. Brasília, 2003. Disponível em: <http://www.planalto.gov.br/CCIVil_03/leis/2003/L10.831.htm>. Acesso em: 30 de abril de 2018.

BRASIL. Decreto $n^{0}$ 6.323, de 27 de dezembro de 2007. Brasília, 2007. Disponível em: $<$ http://www.planalto.gov.br/ccivil 03/ ato2007-2010/2007/ Decreto/D6323.htm>. Acesso em: 08 de maio de 2018.

BUAINAIN, A. M.; BATALHA, M. O. (orgs). Cadeia Produtiva de Produtos Orgânicos. Brasília: Ministério da Agricultura, Pecuária e Abastecimento (MAPA); Secretaria de Política Agrícola (SPA); Instituto Interamericano de Cooperação para a Agricultura (IICA). Série Agronegócios, Vol. 5, 2007.

CAMPANHOLA, C.; VALARINI, P. J. (2001). A agricultura orgânica e seu potencial para o pequeno agricultor. Cadernos de Ciência \& Tecnologia. Brasília, v. 18, n. 3, p. 69-101.

DAROLT, M. R. Alimentos orgânicos: um guia para o consumidor consciente. 2. ed. rev. ampl. - Londrina: IAPAR, 2007.

DIAS, R. Marketing ambiental: ética, responsabilidade social e competitividade nos negócios. São Paulo: Atlas, 2011.

DULLEY, R. D. Agricultura Orgânica, biodinâmica, natural, agroecológica ou ecológica? São Paulo: Informações Econômicas, v. 33, n. 10, out. 2003.

GLIESSMAN, S. R. Agroecologia: processos ecológicos em agricultura sustentável. $4^{\text {a }}$ ed. - Porto Alegre: Editora da Universidade/UFRGS, 2009.

HARKALY, A. Perspectivas da agricultura orgânica no mercado internacional. Boletim Agroecológico, ano III, n. 11, p. 8-11, 1999.

MAPA. Ministério da Agricultura, Pecuária e Abastecimento. Disponível em: $<$ http://www.mda.gov.br/sitemda/noticias/plantar-org\%C3\%A2nicos\%C3\%A9-preservar-o-meio-ambiente $>$. Acesso em: 30 de abril de 2018.

MARTINS, R. K. O Sistema Mandala de Produção de Alimentos: Uma Estratégia Para o Desenvolvimento da Agricultura Familiar. XXI Encontro Nacional de Geografia Agrária. 55 Uberlândia- MG 15 a 19 de outubro de 2012. Disponível em: < http://www.lagea.ig.ufu.br/xx1enga/ anais enga 2012/eixos/1397 1.pdf>. Acesso em 29 de abril de 2018.

MAY, P. H.; LUSTOSA, M. C.; VINHA, V. da (orgs). Economia do meio ambiente: teoria e prática. Rio de Janeiro: Elsevier, 2003.

MILLER JR, G. T. Ciência Ambiental. Tradução de: All Tasks. Revisão técnica de: DELITTI, Welington Braz Carvalho. $11^{\mathrm{a}} \mathrm{ed}$. São Paulo: Cengage Lerning, 2008.

MOTTA, R. S. Padrão de Consumo, distribuição de renda e o meio ambiente no Brasil. Rio de Janeiro: IPEA. Texto para discussão $n^{\circ} 856$, janeiro de 2002.

OTTMAN, J. A. As novas regras do marketing verde: estratégias, ferramentas e inspiração para o branding sustentável. São Paulo: M. Books, 2012.

PAULA, J. de. Desenvolvimento local: como fazer? Brasília : SEBRAE, 2008. Disponível em: $<$ http://www.sebrae.com.br/sites/PortalSebrae/artigos/ desenvolvimento-local-como-fazer,304ad1 eb00ad2410VgnVCM100000b 272010aRCRD>. Acesso em 25 de out de 2018 .

PRIMAVESI, A. Revisão do conceito de agricultura orgânica: conservação do solo e seu efeito sobre a água (palestra). São Paulo: Biológico, v. 65, n.1/2, p. 69-73, jan/dez. 2003.

SEBRAE - Serviço Brasileiro de Apoio às Micro e Pequenas Empresas. Disponível em: $<\underline{\text { http://www.sebrae.com.br/sites/PortalSebrae/artigos/o- }}$ 
mercado-para-os-produtos-organicos-esta-aquecido, 5f48897d3f94e410V gnVCM1000003b74010aRCRD>. Acesso em: 01 de maio de 2018.

WILKINSON, J. Distintos enfoques e debates sobre a produção familiar no meio rural. Rio de Janeiro. 2000.

\section{ANÁLISE TEMPORAL DA IMPLEMENTAÇÃO DO CADASTRO \\ AMBIENTAL RURAL NOS ASSENTAMENTOS RURAIS DO ESTADO DE MATO GROSSO}

Ana Luisa Araujo de Oliveira Vinicius de Freitas Silgueiro ${ }^{2}$ Weslei Butturi ${ }^{3}$

ReSUMo: O presente artigo tem o objetivo de realizar uma análise temporal da implementação do CAR dos assentamentos no estado de Mato Grosso, contemplando o histórico, os avanços e os desafios a serem superados atualmente. Os resultados evidenciam que ao longo do tempo, os entraves para a implementação desse instrumento foram de ordem jurídica e técnica, sendo que muitos esforços foram feitos ao longo de 2017 e 2018 para a construção de soluções que comtemplem a regularização ambiental dos assentamentos. Entre os avanços, destaca-se que o impasse jurídico em relação aos diferentes entendimentos de artigos do Código Florestal foi resolvido, contribuições técnicas para a criação de uma interface para os assentamentos no Sistema Mato-grossense de Cadastro Ambiental Rural (SIMCAR) foram entregues à Secretaria de Estado de Meio Ambiente de Mato Grosso (SEMA/MT) e ao Ministério Público Federal (MPF), assim como foi assinado um Acordo de Cooperação Técnica (ACT) entre a SEMAe o Instituto Nacional de Colonização e Reforma Agrária (INCRA) cujo objeto é justamente a regularização ambiental dos assentamentos. Sobretudo, há a necessidade de uma tomada de decisão da SEMA/MT e plano de trabalho claro para implementação das customizações necessárias ao SIMCAR. Somente após isso, os órgãos fundiários e assentados poderão cumprir com as responsabilidades atribuídas pelo Código Florestal para a regularização

'Doutoranda no Programa de Pós Graduação em Desenvolvimento Rural da Universidade Federal do Rio Grande do Sul (PGDR/UFRGS). E-mail:aluisamt@gmail.com

${ }^{2}$ Especialização em Gest. Int. Sist. Socioeco. Prod. Fam. Amz. Legal pela Universidade do Estado de Mato Grosso, Brasil(2015).Coordenador do Núcleo de Geotecnologias do Instituto Centro de Vida , Brasil. E-mail:

vinicius.silgueiro@icv.org.br
${ }^{3}$ Esp. Eng. Florestal, Analista de Geotecnologias do Instituto Centro de Vida (ICV), Alta Floresta, MT, Brasil. E-mail: weslei.butturi@icv.org.br 